\title{
Mundos da construção: experiências, organização e lutas
}

\section{Worlds of construction: experiences, organisation, and struggles}

\section{Robério S. Souza* Tyrone Cândido**}

\author{
De fato, como podia \\ um operário em construção \\ compreender por que um tijolo \\ valia mais do que um pão? ${ }^{1}$
}

\begin{abstract}
- $m$ várias partes do mundo, ao longo do tempo, grandiosas obras e empreendimentos desafiaram a capacidade humana, exigiram vultosos materiais e recursos e, sobretudo, demandaram o recrutamento de extensa força de trabalho. As construções de estradas, ferrovias, linhas telegráficas, canais, açudes, portos e usinas compõem algumas dessas expressões de engenhosas intervenções humanas, e se constituiu a base do desenvolvimento e dos processos de modernização econômica da maioria dos países, promovendo sensíveis impactos sociais e ambientais.

É comum que as cerimônias de lançamento e de inaugurações dessas grandes obras e empreendimentos sejam marcadas por pomposas celebrações festivas, com o objetivo de construir uma narrativa oficial em reconhecimento da importância e do prestígio de empresários, de engenheiros, das autoridades e dos governantes, reservando ao esquecimento e à invisibilidade personagens fundamentais: a classe trabalhadora.
\end{abstract}

* $\quad$ Professor Titular do Departamento de Ciências Humanas, da Universidade do Estado da Bahia (UNEB). Atua na área de História do Brasil, História Social do Trabalho e da Cultura. Integra o Grupo de Pesquisa Escravidão e Invenção da Liberdade, da UFBA. ORCID: https://orcid.org/0000-0002-5380-3363. E-mail: roberiossouza@ gmail.com.

** Doutor em História Social pela Universidade Federal do Ceará (UFC). Professor do Curso de História da Universidade Estadual do Ceará (UECE), Campus de Quixadá. ORCID: https://orcid.org/0000-0001-80308985. E-mail: tyronecandido@gmail.com.

1 Trecho do poema O operário em construção (1959), de Vinícius de Moraes. 
Submetidos a condições de vida e trabalho de extrema precariedade e vulnerabilidade, homens, mulheres e crianças, maioria muito pobres, constituíam as turmas de trabalhadores da construção que, distantes de seus locais de moradia, se engajavam nas mais diversas obras e empreendimentos para trabalhar geralmente em serviços e atividades braçais de escavar e carregar areia, quebrar e explodir pedras, subir em andaimes, limpar tarefas de terra etc., expondo seus corpos e arriscando suas vidas para tornar realidade projetos, muitas vezes grandiosos, de construção.

Por lidarem com serviços pesados, as turmas de construção costumam ser formadas pelas composições mais desprotegidas da classe trabalhadora, executando suas tarefas a céu aberto, padecendo de doenças, vivendo em acampamentos precários e insalubres, com jornadas laborais extenuantes, muitas vezes sob regimes de trabalho compulsório, recebendo baixos salários, às vezes com pagamentos atrasados, às vezes ficando sem receber, quando não, recebendo quantias insignificantes em decorrência dos arbitrários descontos em suas remunerações, para compensar os custos da alimentação fornecida pelos empregadores. Essa mão de obra da construção civil, até recentemente pouco estudada, são indivíduos que, como disse Karl Marx, compõem a "infantaria ligeira do capital", geralmente proveniente do campo, mas que exercem atividades industriais.

Estudiosos vinculados à história social, alguns incorporando perspectivas de história global e transnacional, a partir de incursões empíricas densas, têm contribuído para que o mundo do trabalho da construção civil e as experiências de seus trabalhadores ganhem cada vez mais visibilidade. É possível compulsar hoje, com mais facilidade, desde pesquisas com cronologias mais limitadas sobre mão de obra da construção de diversas regiões brasileiras e também de outros países - incluindo de empreendimentos transnacionais que resultavam no trânsito e deslocamentos de trabalhadores por fronteiras -, a estudos que englobam uma temporalidade mais ampla, remontando aos primórdios da expansão do capitalismo até nosso tempo presente, com todas as fases de expansão verificadas nos meios de transporte, comunicação e infraestrutura industrial. Nessa direção, a produção historiográfica em curso tem procurado versar sobre as experiências e condições dos trabalhadores nos processos de construção, suas formas de resistência e protestos, intercruzando de forma sofisticada com dimensões de gênero, etnicidade, nacionalidade, raça, qualificação no trabalho, controle de classe, organização sindical e articulações políticas. ${ }^{2}$

2 Não há ainda um balanço sobre a produção historiográfica voltada aos trabalhadores de construção, porém algumas obras podem ser apontadas como referências nos estudos dedicados ao assunto. Em âmbito internacional, Terry Coleman apresentou um estudo pioneiro com seu The railway navvies: a history of the man who made the railways (London: Penguin Books, 1968). Ian J. Kerr escreveu Building the railways of the Raj, 1850-1900 (Delhi, Oxford: University Press, 1995) e Peter Way publicou Common labour: workers and the digging of North American canals, 1780-1860 (Cambridge: Cambridge University Press, 1993). Mais recentemente, Julie Greene lançou The canal builders: making America's empire at the Panama Canal. (New York: Penguin Books, 2009). No Brasil destaca-se a obra de Maria Lúcia Lamounier intitulada Ferrovias e mercado de trabalho no Brasil no século XIX (São Paulo: Editora da Universidade de São Paulo, 2012) e a de Thiago Moratelli: Operários de empreitada: os trabalhadores da construção da estrada de ferro Noroeste do Brasil, São Paulo e Mato Grosso, 1905-1914 (Campinas: Editora da Unicamp, 2013). Há ainda, entre a produção acadêmica, um número crescente de dissertações e teses que abordam a história 
Considerando essas questões, o dossiê "Trabalhadores de construção: por estradas, ferrovias, açudes e outras obras" foi proposto com a intenção de reunir artigos que expressassem uma parte das sólidas trajetórias de pesquisas preocupadas em evidenciar as experiências e as condições laborais dessa multifacetada modalidade de trabalhadores da construção, a partir de casos transcorridos nos mais diferentes tempos e lugares. Assim, portanto, uma diversidade de abordagens faz-se presente nesse dossiê que se inicia com o artigo de Florencia D'Uva. Trata-se de um estudo sobre as experiências dos trabalhadores que atuavam no setor Vía y Obras das ferrovias argentinas durante as primeiras décadas do século XX. Nele, a autora constata que, apesar de haver uma larga produção historiográfica sobre os trabalhadores ferroviários na Argentina, poucos são aqueles que se voltam para os que atuavam no setor de construção e manutenção das vias férreas. Segue uma qualificada apresentação das características do trabalho das chamadas cuadrillas, suas condições de trabalho e a vida nos acampamentos. O texto analisa ainda as memórias de Geniali Giretti, imigrante genovês que passou muitos anos como trabalhador de construção ferroviária na Argentina, enquanto sua família permanecia vivendo na Itália.

Em seguida Tyrone Apollo Pontes Cândido aborda a conflituosa greve dos retirantes da seca de 1888, empregados como construtores da Estrada de Ferro de Baturité no Ceará. O autor busca mostrar como aquela primeira greve ocorrida em obras de socorros públicos durante tempos de estiagem prolongada representou uma incorporação desse consagrado meio de luta dos trabalhadores a outras formas de protesto e resistência dos retirantes. $O$ artigo discute as circunstâncias de formação de classe desses sertanejos e as contradições da implementação das relações assalariadas nas obras de construção. Em sua conclusão, o autor situa a greve dos construtores da ferrovia de Baturité no cenário diversificado de movimentos paredistas ocorridos no século XIX.

Do mesmo ano de 1888 é o caso enfocado pelo artigo de Robério S. Souza e lacy Maia Mata. No cenário das multidões de trabalhadores para a construção da Estrada de Ferro Bahia-Minas, imersas nas tensões que envolviam as relações de escravidão e as lutas do pós-abolição, os autores identificam uma turma de trabalhadores portugueses que reclamaram em frente ao escritório do empreiteiro pelos ordenados pagos em desacordo com o ajustado. O conflito resultou em prisões e no uso de tronco como punição física a trabalhadores de condição livre. Os autores refletem então sobre o mandonismo que prevaleceu nas relações de trabalho ainda durante o pós-abolição, sinalizando para o legado da escravidão.

O dossiê segue com o artigo de Yuri Simonini que trata da presença anônima dos trabalhadores de construção do porto de Natal nos anos da passagem do século XIX para o século XX, em especial os retirantes das secas, uma população adventícia de "indesejados"

dos trabalhadores de construção a partir de enfoques localizados de pesquisas gestadas em diversos programas de pós-graduação. 
na capital potiguar. Segundo o autor, se as primeiras medidas de emprego de retirantes nas obras de contenção das águas no bairro da Ribeira remontam às últimas décadas do século XIX, apenas no período republicano é que serviços de efetiva construção portuária teriam início, porém seus trabalhadores continuariam a figurar nas sombras.

No artigo de autoria de Renata Felipe Monteiro, novamente são os retirantes das secas a figurarem como construtores, dessa vez do grande açude do Cedro, em Quixadá, cidade situada no sertão central do Ceará. A autora discute a caracterização da construção do açude Cedro, construído entre 1884 e 1906, explorando considerações acerca de sua utilidade como grande empreendimento que visava resolver os problemas das secas, desenvolver práticas agrícolas modernas e melhorar a vida da população. Renata Monteiro observa uma mudança de perspectiva nos anos desde sua inauguração, quando considerações mais pessimistas são expressas a respeito das possibilidades daquela obra promover mudanças e melhorias significativas para o território das secas. Essa alteração tem a ver com os altos custos financeiros que a obra demandou, como também com a dureza das experiências de trabalho das numerosas multidões de retirantes nela empregados.

Luciano de Moura Guimarães é o autor de artigo que se propõe a identificar o papel dos trabalhadores da construção civil no movimento operário de Salvador entre os anos de 1919 e 1922, tempo da greve geral de 1919, do Primeiro Congresso Operário da Bahia, da criação da Federação de Trabalhadores da Bahia e outros eventos e protestos. Acompanhando a trajetória de Agripino Nazareth e Eustáquio Marinho no seio da Sociedade de Pedreiros, Carpinteiros e Demais Classes (SPCDC), o autor indica a presença das tendências socialista e anarquista no movimento dos trabalhadores de construção civil na cidade de Salvador.

O artigo de Lara Vanessa de Castro Ferreira aborda, por sua vez, as condições de trabalho daqueles que qualifica como "trabalhadores-cassacos" nas frentes de trabalho acionadas durante as secas da década de 1950, especificamente no estado do Ceará. Seu texto analisa o cotidiano do trabalho, englobando o conjunto das obras acionadas por instituições como DNOCS, sobretudo açudes e estradas, onde trabalhadores do semiárido brasileiro viveram um cotidiano particularmente penoso de escassez, condições insalubres e maus-tratos.

O dossiê conta ainda com a contribuição de Renata Silva Gusmão, cujo artigo aborda as condições de trabalho dos construtores do estádio Trapichão, em Maceió, edificado durante a ditadura civil-militar, entre março de 1968 e outubro de 1970, num prazo recorde. A autora relaciona o favorecimento do regime aos setores empresariais com a piora das condições de trabalho dos operários da construção civil, precarização que resultava em altos índices de ferimentos e doenças, superexploração e um cotidiano destituído de recursos básicos de segurança e bem-estar. $\mathrm{O}$ artigo recorre ainda a um levantamento de processos trabalhistas que revelam as ações dos trabalhadores na luta por direitos, mas também as adversidades encontradas na Justiça do Trabalho. 
Fechando nosso dossiê, encontra-se artigo de Nathalia Capellini, onde analisa a construção da usina hidrelétrica de Tucuruí, no Pará, entre 1974 e 1984, discutindo a estratégia de estabelecimento de uma cidade-empresa anexa ao canteiro de obras na finalidade de alcançar uma maximização da produtividade por meio de um estreito controle da mão de obra. Trata-se de um histórico dos trabalhadores de construção, sobretudo daqueles que trabalhavam nos grandes empreendimentos acionados durante o regime ditatorial entre os anos 1970 e 1980, que ficaram conhecidos como os "peões de barragem".

Os artigos assim reunidos nesse dossiê apresentam não somente uma parcela da produção atual da história social do trabalho relacionada a trabalhadores de construção em diversas obras e em diferentes temporalidades. São também um chamado público à reflexão sobre as experiências e as lutas desses imprescindíveis sujeitos, anônimos construtores da história. Ou como dizia o poeta: "o operário faz a coisa e a coisa faz o operário". 